\title{
Perencanaan Saluran Drainase pada Jalan Donowarih Kecamatan Karangploso Kabupaten Malang
}

\author{
Suhudi ${ }^{1}$ dan Harvi Irvani ${ }^{2}$ \\ 1,2 Jurusan Teknik Sipil Fakultas Teknik Universitas Tribhuwana Tunggadewi Malang \\ J1.Telaga Warna Blok C Tlogomas Malang, 65114, Indonesia \\ Email : suhudi@unitri.ac.id
}

\begin{abstract}
ABSTRAK
Sistem drainase sangat dibutuhkan untuk mencegah terjadinya genangan air, membuang air hujan yang tidak terserap dalam tanah, serta membuat lingkungan sekitar menjadi tidak sehat. Kecamatan Karangploso merupakan Kecamatan yang menjadi pusat perekonomian, sosial, dan aktivitas pemerintah daerah. Namun terdapat permasalahan banjir atau genangan air yang menjadi pemikiran dan perhatian dari berbagai pihak, Ini disebabkan minimnya saluran drainase di dalam maupun sekitar wilayah Kecamatan Karangploso. Penelitian ini dilaksanakan di dusun Borogragal Desa Donowarih, Kecamatan Karangploso Kabupaten Malang. Metode penelitian yang digunakan adalah metode Rasional yakni $\mathrm{Qa}=0.00278$. C.I.A, menggunakan analisa hidrologi, data curah hujan dan peta tata guna lahan. Dari hasil analisis data menyatakan bahwa jumlah curah hujan dengan kala ulang 10 tahun. Debit banjir kala ulang 10 tahun sebesar: Q sal. $=1,0 \mathrm{~m} 3 /$ detik. Kapasitas saluran drainase yang ada sebesar Q sal. $=0,389 \mathrm{~m} 3 /$ detik. Dimensi saluran yang ada tidak cukup untuk melewatkan debit banjir kala ulang 10 tahun sebesar 1,0 m3/ detik. Rencana saluran drainase sebesar: Q sal. $=0,410 \mathrm{~m} 3 /$ detik. Desain konstruksi untuk saluran drainase di jalan adalah $\mathrm{b}=0,60 \mathrm{~m}$ dan $\mathrm{h}=0,80 \mathrm{~m}$. Untuk menjaga agar tidak terjadi genangan maka dihimbau kepada masyarakat agar tidak membuang sampah pada saluran dan mengadakan pemeliharaan secara rutin oleh Dinas terkait dan juga masyarakat.
\end{abstract}

Kata Kunci : drainase; banjir; curah hujan; analisa hidrologi

\begin{abstract}
The drainage system is needed to prevent the occurrence of puddles, dispose of rainwater that is not absorbed in the soil, and make the surrounding environment unhealtby. Karangploso sub-district is a sub-district which is the center of economic, social and local government activities. However, there are problems of flooding or puddles which are the thoughts and concerns of various parties, this is due to the lack of drainage channels in and around the Karangploso District area. This research was carried out in the Borogragal hamlet of Donowarib Village, Karangploso District, Malang Regency. The research method used is the Rational method, namely $Q_{a}=0.00278$. C.I. A, uses bydrology analysis, rainfall data and land use maps. From the results of the data analysis states that the amount of rainfall with a return period of 10 years. 10 year return flood discharge for: $Q$ sal. $=1.0 \mathrm{~m} 3 /$ second. The existing drainage channel capacity is as big as $Q$ sal. $=0.389 \mathrm{~m} 3 /$ second. The existing channel dimensions are not enough to pass a 10-year return flood discharge of $1.0 \mathrm{~m} 3$ / sec. Drainage plan is as big as: $Q$ sal. $=0.410 \mathrm{~m} 3$ / sec. The construction design for drainage lines on the road is $b=0.60 \mathrm{~m}$ and $h=0.80 \mathrm{~m}$. In order to prevent inundation, the community is advised not to dispose of garbage on the canal and to carry out routine maintenance by related agencies and the community.
\end{abstract}

Keywords : drainage; flood; rainfall; hydrology analysis

Cara Mengutip : Suhudi, Irvani, H. (2019). Perencanaan Saluran Drainase pada Jalan Donowarih Kecamatan Karangploso Kabupaten Malang. Reka Buana : Jurnal Ilmiab Teknik Sipil dan Teknik Kimia, 4 (1), 49-56. http://dx.doi.org/10.33366/rekabuana.v4i1.1196 


\section{PENDAHULUAN}

Banjir merupakan satu hal yang sering terjadi di Indonesia, khususnya pada musim hujan mengingat hampir semua di kota Indonesia mengalami bencana banjir, peristiwa ini hampir setiap tahun terulang namun permasalahan ini sampai saat ini belun terselesaikan, bahkan cenderung makin meningkat, baik frekuensinya, luasnya, kedalamanya maunpun durasinya.

Kecamatan Karangploso

Kabupaten Malang), merupakan kecamatan yang letaknya cukup strategis dengan perkembangan dan peningkatan masyarakat di kota tersebut, sehingga bertambah pula sarana dan prasarana yang mendukung, Salah satunya adalah sistem pembangunan dan saluran drainase. Dengan perkembangan Kecamatan Karangploso, sistem drainase sangat dibutuhkan untuk membuang air hujan yang tak dapat terserap dalam tanah,serta mencegah terjadinya genangan air yang dapat mengganggu aktivitas masyarakat dan membuat lingkungan menjadi tidak sehat. Terjadinya banjir atau genangan air menambah permasalahan di Kecamatan Karangploso, padahal itu merupakan Kecamatan pusat aktivitas pemerintah daerah.

Permasalahan banjir atau genangan air menjadi pemikiran dan perhatian dari berbagai pihak, Ini disebabkan minimnya saluran drainase di dalam maupun sekitar wilayah Kecamatan Karangploso. Oleh karena itu, cukup mempengaruhi kehidupan masyarakat baik dalam hal keindahan, kesehatan, ekonomi maupun sosial budaya.

Studi ini membahas tentang perencanaan saluran drainase pada jalan dusun Borogragal. Dengan mempelajari kawasan studi perencanaan jalan yang berada di Kecamatan Karangploso Kabupaten
Malang, Kemudian membuat perencanaan saluran drainase pada jalan. Perencanaan perbaikan sistem drainase sesuai dengan kebutuhan sekarang berdasarkan permasalahan yang ada. Tujuan penelitian ini untuk mengetahui dimensi saluran yang ada mampu mengalirkan debit aliran maksimum untuk memperoleh debit rencana saluran drainase dengan kala ulang 10 tahun. Selain itu merencanakan kembali saluran drainase tersebut, agar kapasitasnya bertambah dan mampu mengalirkan debit aliran maksimum. Drainase Perkotaan adalah sistem jaringan pembuangan di wilayah yang berfungsi mengelola dan mengendalikan air permukaan, sehingga tidak mengganggu bahkan merugikan bagi kehidupan manusia. Secara prinsip sistem drainase berfungsi untuk mengelola air kelebihan dengan cara meresapkan sebanyak-banyaknya air ke dalam tanah secara alamiah atau mengalirkan air ke badan air penerima, seperti sungai atau laut, tanpa melampaui kapasitas badan air yang ada.

\section{Analisa Hidrologi}

Perencanaan saluran drainase, baik drainase perkotaan, pertanian maupun drainase pasang surut sudah pasti membutuhkan analisa hidrologi, karena dalam perencanaan saluran drainase, salah satu komponen utama yang harus diperhitungkan adalah jumlah air masuk ke saluran drainase, seperti air hujan dan limbah rumah tangga atau industry [1]. Data-data diperoleh dengan analisa hidrologi sehingga analisa hidrologi menjadi bagian penting dalam perencanaan saluran drainase.

\section{Curah Hujan Rata-Rata Daerah}

Curah hujan yang diperlukan untuk menyusun suatu rancangan pemanfaatan air dan pengendalian banjir adalah curah hujan 
rata-rata di seluruh daerah terkait. Bukan curah hujan pada suatu titik tertentu. Curah hujan ini disebut curah hujan daerah yang dinyatakan dalam milimeter. Untuk mendapatkan gambaran mengenai penyebaran hujan di beberapa tempat, maka dipasang alat penakar hujan pada DAS.

\section{Hujan Rancangan Maksimum}

Hujan Rancangan maksimum adalah curah hujan terbesar tahunan yang mungkin terjadi di suatu daerah dengan kala ulang tertentu. Berbagai metode yang dapat dipakai dalam menganalisa curah hujan rancangan antara lain distribusi (Gumbel, Log Normal, Log Perason Type III) dan lain-lain.

Untuk menentukan jenis analisa frekuensi, perlu dihitung parameterparameter statistik seperti koefisien Cs, Cv, Ck.Syarat untuk distribusi :

- E.J Gumbel : $\mathrm{Ck}=5,4$ dan $\mathrm{Cs}=1,14$

- Log Normal : $\mathrm{Ck}=3,0$ dan $\mathrm{Cs}=0,0$

- Log Pearson III: Ck dan Cs bebas

\section{Koefisien Pengaliran}

Koefisien pengaliran adalah perbandingan antara jumlah air yang mengalir di suatu daerah akibat turunnya hujan dengan jumlah air hujan yang turun di daerah tersebut. Koefisien pengaliran pada suatu daerah dipengaruhi oleh faktor-faktor penting. Besarnya koefisien pengaliran berubah dari waktu ke waktu sesuai dengan pengaruh pemanfaatan lahan dan aliran sungai.

\section{Kapasitas Saluran}

Kapasitas Saluran dihitung menggunakan rumus-rumus sebagai berikut :

1. Kecepatan

$$
\mathrm{V}=\frac{1}{n} \mathrm{R}^{2 / 3} \cdot \mathrm{S}^{1 / 2}
$$

2. Kontinuitas

$$
\mathrm{Q}=\mathrm{A} . \mathrm{V} \text {. }
$$

Dimana :

$\mathrm{V}=$ kecepatan aliran pada saluran $(\mathrm{m} / \mathrm{s})$

$\mathrm{R}=$ jari-jari hidrolis $(\mathrm{m})$

$\mathrm{n}=$ koefisien kekasaran Mannning

$\mathrm{A}=$ luas penampang basah $\left(\mathrm{m}^{2}\right)$

$\mathrm{Q}=\operatorname{debit}\left(\mathrm{m}^{3} / \mathrm{s}\right)$

$\mathrm{R}=\mathrm{A} / \mathrm{P}$

$\mathrm{P}=$ keliling basah saluran (m)

Pada tabel 1 berikut ini akan ditampilkan lebar saluran yang dianjurkan berdasarkan kapasitas saluran air.

Tabel 1. Perbandingan lebar dasar saluran yang dianjurkan sesuai dengan kapasitas saluran

\begin{tabular}{cc}
\hline Kapasitas Saluran & b:h \\
\hline $0,0-0,5$ & 1,0 \\
$0,5-1,0$ & 1,5 \\
$1,0-1,5$ & 2,0 \\
\hline $1,5-3,0$ & 2,5 \\
$3,0-4,5$ & 3,0 \\
$4,5-6,0$ & 3,5 \\
$6,0-7,5$ & 4,0 \\
$7,5-9,0$ & 4,5 \\
$9,0-11,0$ & 5,0 \\
\hline
\end{tabular}

(Sumber: Subardjono, 2013) [2]

\section{METODE PENELITIAN}

Lokasi saluran drainase jalan di Dusun Borogragal terletak di kecamatan Karangploso Kabupaten Malang, merupakan saluran drainase alam yang dilalui jalur utama yang menghubungkan kota Surabaya dan Kota Batu.

Peneliti melakukan survey lokasi di Dusun Borogragal Desa Donowarih Kecamatan Karangploso Kabupaten Malang untuk melihat langsung konsidi perencanaan saluran drainase jalan. Kemudian menggunakan data tata guna lahan daerah studi untuk mengetahui fungsi daerah sekitar lahan dan untuk mengetahui langkah yang paling efektif dalam pengendalian banjir tersebut. 


\section{Pengumpulan Data}

Dalam Proses Pengumpulan ada 2 Jenis Data yang digunkan adalah sebagai berikut :

1. Data Primer

2. Data Sekunder

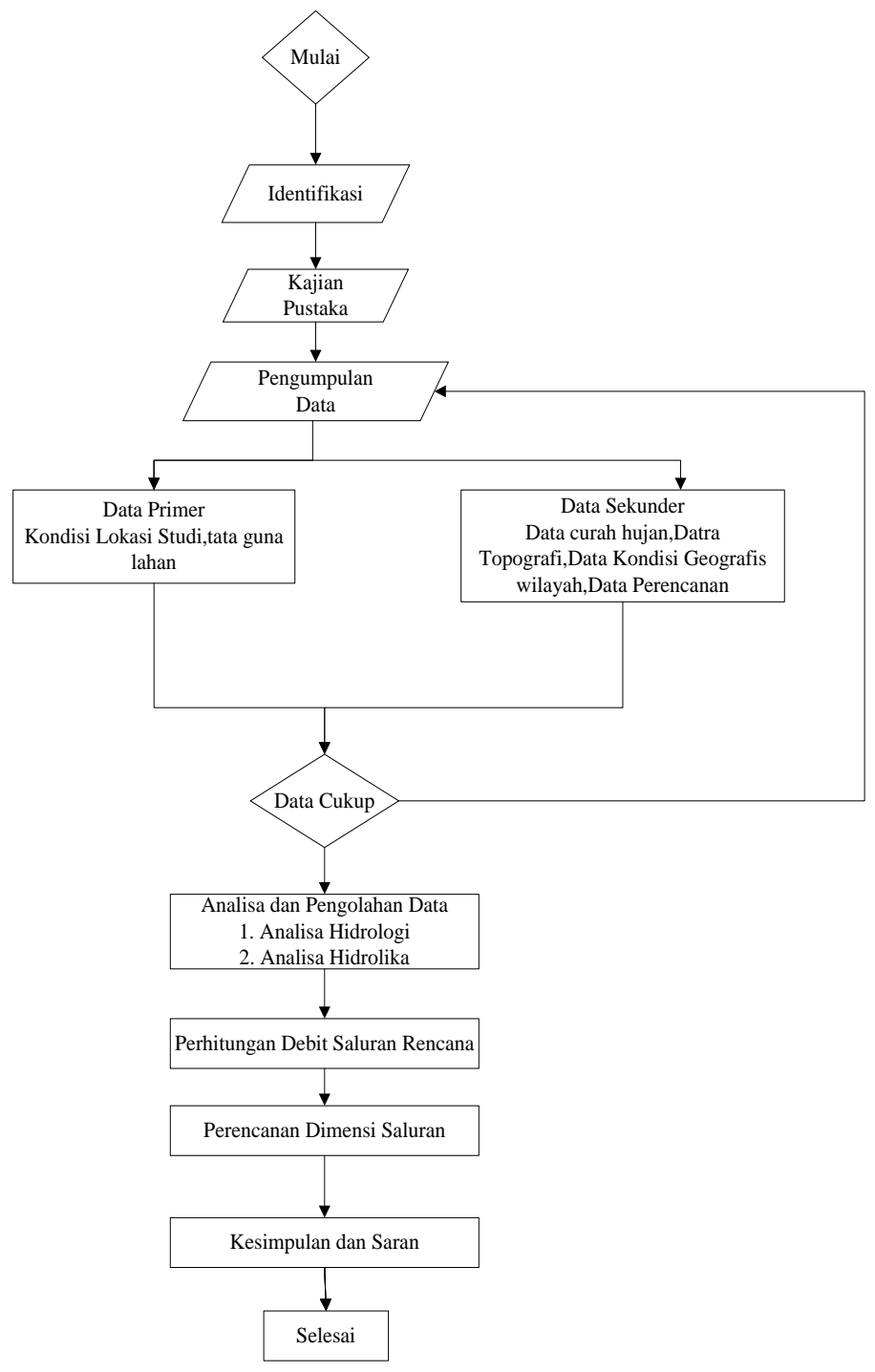

Gambar 1. Diagram Alir Penelitian

\section{HASIL DAN PEMBAHASAN}

Untuk Menganalisa suatu masalah diperlukan adanya data. Data yang dibutuhkan digolongkan menjadi dua jenis, yaitu Data Primer dan Data Sekunder. Data primer merupakan data yang di peroleh dari hasil pengukuran atau pengamatan secara langsung. Sedangkan data Sekunder merupakan data yang didapat dengan cara mengutip dari berbagai sumber yang dapat di pertanggungjawabkan kebenarannya.

Dalam studi ini, data yang digunakan adalah data sekunder. Data-data tersebut meliputi data curah hujan, data topografi, data kondisi georafis wilayah dan data perencanaan. Berdasarkan data curah hujan harian 10 tahunan dapat dilihat pada lampiran, sehingga diperoleh curah hujan harian maksimum dapat dilihat pada tabel 2 berikut:

Tabel 2. Curah Hujan Maksimum

\begin{tabular}{cc}
\hline Tahun & R24 Maks $(\mathrm{mm})$ \\
\hline 2006 & 105 \\
\hline 2007 & 35 \\
\hline 2008 & 98 \\
\hline 2009 & 140 \\
\hline 2010 & 125 \\
\hline 2011 & 93 \\
\hline 2012 & 90 \\
\hline 2013 & 111 \\
\hline 2014 & 115 \\
\hline 2015 & 86 \\
\hline Sumber : Analisa Perbitungan
\end{tabular}

\section{Curah Hujan Maksimum}

Setelah diketahui tinggi curah hujan harian maksimum rata-rata, maka dengan menggunakan metode Log Pearson III dapat dihitung besarnya curah hujan rancangan yang terjadi pada $\mathrm{T}$ tahun. Untuk menentukan curah hujan rancangan di gunakan analisa frekuensi log pearson III [3]. Berikut akan disajikan hasil analisa rancangan frekuensi hujan dengan metode log pearson type III pada tabel 3. 
Tabel 3. Hujan Rancangan Dengan Menggunakan Metode Log Pearson Type III

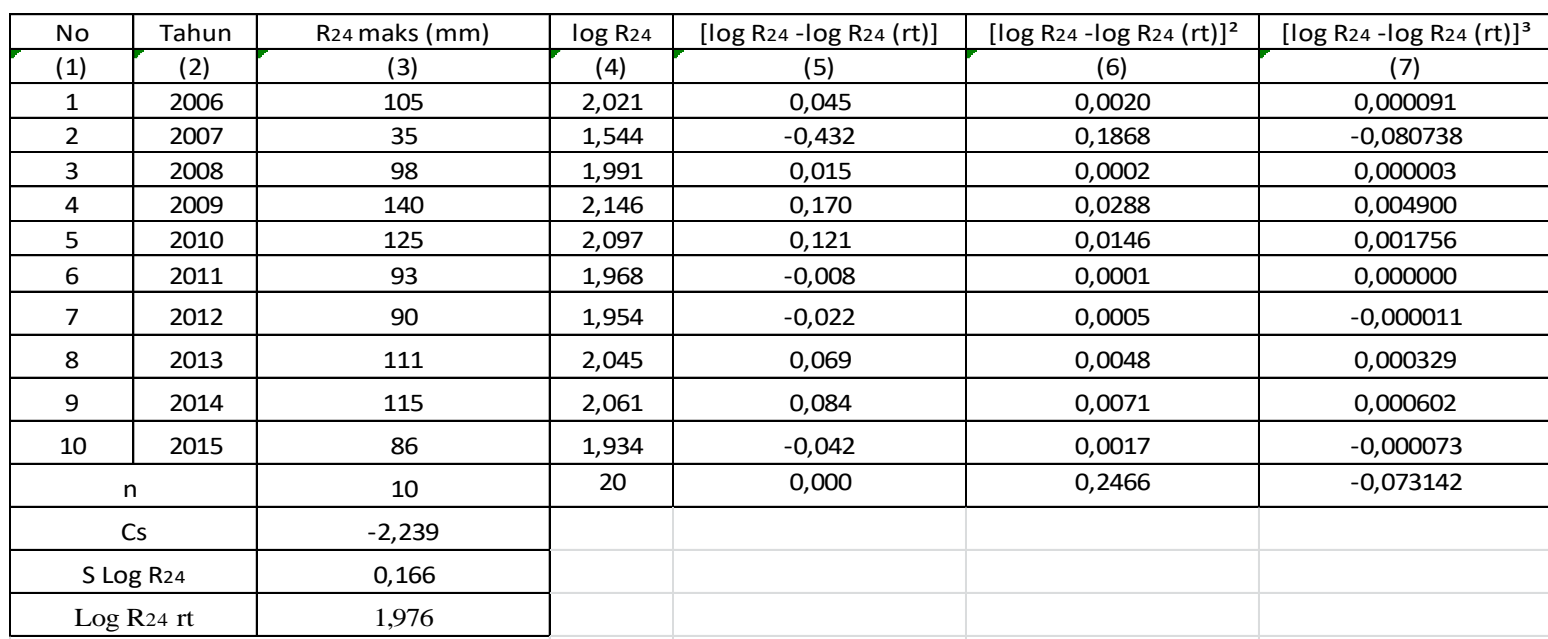

Sumber : Analisa Perhitungan

Keterangan :

1. Nomor

2. Tahun

3. Rata- rata Maksimun Stasiun Curah Hujan Singosari

4. Logaritma Rata-rata Curah Hujan Maksimum

5. Rata-rata Maksimum Tahun - Rata-rata Maksimum Banyaknya Data

6. Rata-rata Maksimum Tahun - Rata-rata Maksimum Banyaknya Data Pangkat Dua(2)

7. Rata- rata Maksimum Tahun - Rata-rata Maksimum Banyaknya Data Pangkat Tiga(3)

1. Harga Rata - rata

$$
\begin{aligned}
\log \bar{x} & =\frac{\sum_{i=l}^{n} \log X_{i}}{n} \\
& =\frac{2,049}{10}=0,2049(\mathrm{~mm})
\end{aligned}
$$

2. Simpangan baku (Sd):

$$
\begin{aligned}
S_{x} & =\sqrt{\frac{\sum\left(\log X_{i}-\log \bar{X}_{i}\right)^{2}}{n-1}} \\
& =\sqrt{\frac{0,0008}{10-1}}=2,049
\end{aligned}
$$

3. Koefisien Kemencengan (Cs):

$$
\begin{gathered}
C s=\mathrm{G}=\frac{n \sum_{i=l}^{n}\left(\log X_{i}-\log \bar{X}_{i}\right)^{3}}{(n-1)(n-2)(S d)^{3}} \\
\mathrm{Cs}=\frac{10 \cdot(-0,0059)}{(10-1)(10-2)(0.281)^{3}}=\mathbf{0 , 8 6 8}
\end{gathered}
$$

Tabel 4. Uji Distribusi Che-Square, Perhitungan Nilai $\mathrm{X}_{\mathrm{T}}(\mathrm{mm})$

\begin{tabular}{|c|c|c|c|c|c|c|c|c|}
\hline \multirow{2}{*}{ No } & Kala Ulang & $\mathrm{P}$ & \multirow{2}{*}{$\mathrm{K}$} & \multirow{2}{*}{$\mathrm{S} \log \mathrm{R}_{24}$} & \multirow{2}{*}{$\mathrm{K} * \mathrm{~S} \log \mathrm{R}_{24}$} & \multirow{2}{*}{$\log \mathrm{R}_{24} \mathrm{rt}$} & \multirow{2}{*}{$\log \mathrm{X}_{\mathrm{T}}$} & $\mathrm{X}_{\mathrm{T}}$ \\
\cline { 2 - 6 } & (Tahun) & $(\%)$ & & & & $(\mathrm{mm})$ \\
\hline$(1)$ & $(2)$ & $(3)$ & $(4)$ & $(5)$ & $(6)$ & $(7)$ & $(8)$ & $(9)$ \\
\hline 1 & 2 & 50 & 0,045 & 0,166 & 0,00749 & 1,976 & 1,984 & 96,331 \\
\hline 2 & 5 & 20 & 0,852 & 0,166 & 0,14107 & 1,976 & 2,117 & 131,022 \\
\hline 3 & 10 & 10 & 1,249 & 0,166 & 0,20670 & 1,976 & 2,183 & 152,397 \\
\hline 4 & 25 & 4 & 1,653 & 0,166 & 0,27370 & 1,976 & 2,250 & 177,818 \\
\hline
\end{tabular}

Sumber: Analisa Perhitungan 
Keterangan :

1.Nomor

2. Kala Ulang Tahunan Berdasarkan Tipologi Kota

3. Probabilitas (Kemungkinan yang dapat terjadi dalam suatu peristiwa tertentu)

4. Faktor Frekuensi K dari Tabel Nilai Distribusi Log Person Tipe III

5. Standart Deviasi Logaritma

6. (4)*(5)

7. Logritma Rata-rata Curah hujan Mkasimum Banyaknya Data

8. (6)+(7)

9. Antilog (8)

\section{Perhitungan Kapasitas Saluran Rencana}

Perhitungan kapasitas saluran rencana direncanakan :

Lebar dasar saluran $(\mathrm{b})=0,60 \mathrm{~m}$

Tinggi muka air $(\mathrm{h}) \quad=0,080 \mathrm{~m}$

Kekasaran dinding saluran pasangan Batukali ( $\mathrm{n}$ ) : 0,030

Kemiringan dasar saluran ( $\mathrm{s})=0,005$

Jenis saluran $=$ Persegi

\section{Keterangan:}

a. Lebar Dasar Saluran (b)

b. Tinggi Muka Air (h)

c. Pasangan Batukali (n)

d. Kemiringan Dasar Saluran (s)
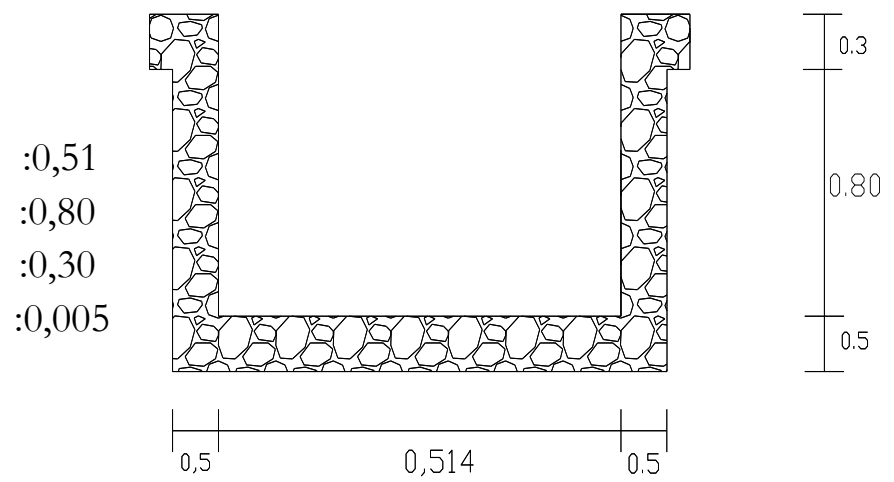

Gambar 2. Perencanaan Saluran

Tabel 5. Analisa Kapasitas Saluran

\begin{tabular}{|c|c|c|c|c|c|c|c|c|c|c|c|c|}
\hline \multicolumn{13}{|c|}{ Tabel Analisa Kapasitas Saluran } \\
\hline & Nama & $\mathrm{L}$ & $\mathrm{n}$ & $S$ & $b$ & $\mathrm{~h}$ & A & $P$ & $R$ & V & Q & $\mathrm{Fb}$ \\
\hline \multirow[t]{2}{*}{\begin{tabular}{|l|} 
No \\
\end{tabular}} & Saluran & (m) & & & (m) & (m) & (m2) & (m) & (m) & (m/det) & (m3/det) & (m) \\
\hline & 1 & 2 & 3 & 4 & 5 & 6 & 7 & 8 & 9 & 10 & 11 & 12 \\
\hline \multirow[t]{2}{*}{1} & Drainase & 1000 & 0,030 & 0,005 & 0,60 & 0,80 & 0,48 & 2,20 & 0,22 & 0,85 & 0,410 & 0,30 \\
\hline & & & & & & & & & & & 0,389 & \\
\hline \multicolumn{13}{|c|}{ Keterangan } \\
\hline \multicolumn{6}{|c|}{ 1. Nama Saluran } & \multicolumn{6}{|c|}{ 7. Luas Saluran } & \\
\hline \multicolumn{6}{|c|}{ 2. Panjang Saluran (Hulu ke Hilir) } & \multicolumn{6}{|c|}{ 8. Panang Keliling Basah Saluran } & \\
\hline \multicolumn{6}{|c|}{ 3. Koefisien Nilai Kekasaran Saluran } & \multicolumn{6}{|c|}{ 9. Jari-jari Hidrolis } & \\
\hline \multicolumn{6}{|c|}{ 4. Kemiringan Dasar Saluran } & \multicolumn{6}{|c|}{ 10. Kecepatan Aliran } & \\
\hline \multicolumn{6}{|c|}{ 5. Lebar Dasar Saluran } & \multicolumn{6}{|c|}{ 11. Debit saluran } & \\
\hline \multicolumn{6}{|c|}{ 6. Tinggi Saluran } & \multicolumn{6}{|c|}{ 12. Tinggi Jagaan } & \\
\hline
\end{tabular}




\section{Tabel 6. Besaran Angka Kekasaran Manning (n) dan Tinggi Jagaan}

\begin{tabular}{|c|l|c|}
\hline No & Bahan pembuat daftar dan dinding saluran & n \\
\hline A & Saluran tertutup dengan aliran sebagian penuh & \\
\hline 1 & Gorong-gorong dari beton pra cetak & $0,011-0,015$ \\
\hline 2 & Gorong-gorong dari baja & $0,013-0,017$ \\
\hline 3 & Gorong-gorong baja bergelombang & $0,021-0,030$ \\
\hline 4 & Gorong-gorong tanah liat bakar & $0,011-0,013$ \\
\hline B & Saluran terbuka & \\
\hline 1 & Plesteran semen & $0,011-0,015$ \\
\hline 2 & Beton & $0,014-0,019$ \\
\hline 3 & Pasangan bata & $0,012-0,018$ \\
\hline 4 & Pasangan batu kali & $0,017-0,030$ \\
\hline 5 & Tanah asti bersih & $0,016-0,020$ \\
\hline 6 & Tanah berumput & $0,025-0,033$ \\
\hline 7 & Batu padas & $0,025-0,040$ \\
\hline 8 & Tanah tidak terawat/saluran alam & $0,050-0,150$ \\
\hline
\end{tabular}

\section{Tinggi Jagaan}

\begin{tabular}{|l|l|c|c|}
\hline No. & Debit $\left(\mathbf{m}^{3} /\right.$ det $)$ & Tinggi air $\mathbf{h}(\mathbf{m})$ & Tinggi Jagaan $\mathbf{f b}(\mathbf{m})$ \\
\hline 1 & Kurang dari 2,00 & $<1,00$ & 0,30 \\
\hline 2 & $2,00-10,00$ & $1,00-2,00$ & 0,60 \\
\hline 3 & Lebih dari 10,00 & $>2,00$ & 0,80 \\
\hline
\end{tabular}

\section{KESIMPULAN}

Dari hasil dan pembahasan maka di ambil kesimpulan sebagai berikut :

1. Dari hasil analisa menggunakan program running Global Mapper yang di lakukan terdapat dua daerah tangkapan air yang berpengaruh terhadap lokasi studi atau rencana saluran drainase seluas 30,05 $\mathrm{Ha}$.

2. Dari hasil analisa menggunakan program Google Earth dapat direkap peruntukan sebagai berikut :

- Lahan kosong 7,66 Ha

- Perumahan keluarga tunggal 2,63 Ha

- Perumahan berdempetan 4,29 Ha
- Semak berlukar 2,26 Ha

- Sawah 11,95 Ha

- Jalan 1,75 Ha

- Hutan 0,51 Ha

3. Dari hasil analisa menggunakan metode rasional untuk menghitung debit banjir rancangan di peroleh :

- Kala ulang 2 thn (Q : 0,248 m3/det)

- Kala ulang 5 thn (Q : 0,325 m3/det)

- Kala ulang 10 thn (Q : 0,371 m3/det)

- Kala ulang 25 thn (Q : 0,424 m3/det)

4. Dari hasil survey kondisi lahan serta hasil analisa, dipilih saluran segi empat dengan dimensi : 
- Lebar dasar saluran (b : 0,60 m)

- Tinggi saluran (h : 0,80 m)

- Tinggi Jagaan ( $\mathrm{Fb}: 0,30 \mathrm{~m})$

-Tinggi Panjang Saluran (L:1000 m)

\section{DAFTAR PUSTAKA}

[1] Harto, S. 2009. Analisis Hidrologi. PT. Gramedia Pustaka Utama. Jakarta.
[2] Suhardjono. (2013). Drainase Perkotaan. Malang: Jurusan Teknik Pengairan Universitas Brawijaya.

[3] Suripin. 2004. Sistem Drainase Perkotaan yang Berkelanjutan. Penerbit Andi, Yogyakarta.

[4] Suripin. 2010. Sistem Drainase Perkotaan yang Berkelanjutan II. Penerbit Andi, Yogyakarta.

[5] Wesli.(2008). Drainase Perkotaan. Yogyakarta: Graha Ilmu. 